\title{
Interspecific Lily Hybrids with the Ability to Flower Precociously and to Produce Multiple Flower Stalks from Lilium formosanum
}

\author{
Hiroki Saruwatari ${ }^{1}$, Yuka Shuto-Nakano${ }^{1}$, Kanehiro Nakano ${ }^{1}$, Michikazu Hiramatsu2*, \\ Yukio Ozaki ${ }^{2}$ and Hiroshi Okubo ${ }^{2}$ \\ ${ }^{1}$ Graduate School of Bioresource and Bioenvironmental Sciences, Kyushu University, Fukuoka 812-8581, Japan \\ ${ }^{2}$ Faculty of Agriculture, Kyushu University, Fukuoka 812-8581, Japan
}

Lilium formosanum Wallace has remarkable traits such as 'precocious flowering' ability, i.e., it reaches anthesis within 12 months from seed germination, with multiple shooting of flower stalks. To verify the possibility of the usefulness of these traits in lily breeding, nine combinations of interspecific crosses $(L$. formosanum as the seed parent; L. auratum, L. speciosum, L. regale, 'Lollypop', 'Pink Tiger', 'Zaza', 'Le Reve', 'Marco Polo', and 'African Queen' as pollen parents) were carried out with cut-style pollination and ovary-slice culture. Germination was observed in all nine interspecific crosses and 53 hybrids were obtained. Thirty (56.6\%) of the 53 hybrids and two self-pollinated progenies of $L$. formosanum reached anthesis within 24 months from germination through ovaryslice culture. Multiple shooting of flower stalks was recognized in $11(36.7 \%)$ of those flowered hybrids. Four hybrids, the pollen parents of which were Asiatic hybrid lilies with colored flowers, expressed 'precocious flowering' ability, multiple shooting of flower stalks, and entirely colored flowers simultaneously. These results suggest the possibility of breeding new types of cultivars with triple favorable traits from the cross between L. formosanum and Asiatic hybrid lilies with colored flowers.

Key Words: Breeding, Lilium formosanum, Multiple shooting of flower stalks, 'Precocious flowering'.

\section{Introduction}

Most Lilium cultivars are commercially propagated vegetatively by 'scaling' (McRae, 1998), which reduces the effort and time required for flowering and rapid propagation of many clones. It usually takes two years for Oriental hybrid lilies propagated by scaling to achieve the size of a flowering plant (Enami, 2005). Lilium species take several years to start flowering from the time of seed sowing; for example, $L$. auratum Lindley, L. speciosum Thunb., and L. rubellum Baker take 4-5 years (Shimizu, 1971). Lilium formosanum Wallace, native to mainland Taiwan, exceptionally reaches anthesis within 12 months from the time of seed germination without temperature control during the entire cultivation (Hiramatsu et al., 2002). The strong 'precocious flowering' ability of this species is a highly attractive trait in lily cut flower production for obtaining flowers in a short cultivation period and for rapid rotation of the breeding cycle.
The 'precocious flowering' ability has been utilized in interspecific hybrid between L. formosanum $\times$ L. longiflorum Thunb. from 1951 (Shimizu, 1971). The hybrid cultivar is now taxonomically named $L . \times$ formolongi and it is mainly propagated by seeds to produce its cut flowers (Shimizu, 1971). Recently, many intersectional hybrids have been produced by crossing $L . \times$ formolong $i$ with other species and their cultivars (Matsumoto et al., 1998; Mitsunaga et al., 1996, 2002; Okada et al., 1997; Okazaki et al., 1992). Their 'precocious flowering' ability, however, has not been definitely evaluated.

Another attractive trait of $L$. formosanum is the multiple sprouting of flower stalks (Inagaki, 2002; Shii, 1983). Although the trait is considered useful for developing novel lily cultivars, it has also never been used for extensive breeding. Thus, we attempted to obtain intersectional hybrids between $L$. formosanum and other Lilium species or cultivars to evaluate the heritability of the two above-mentioned traits of $L$. formosanum in hybrid progenies. 


\section{Materials and Methods}

\section{Plant materials}

Lilium formosanum (section Leucolirion 6b) grown in our experimental field was used as the female parent. L. formosanum (control), L. auratum (Archelirion), L. speciosum (Archelirion), L. regale Wilson (Leucolirion 6a), three Asiatic hybrids ('Lollypop', 'Pink Tiger', and 'Zaza'), two Oriental hybrids ('Le Reve' and 'Marco Polo'), and one trumpet hybrid ('African Queen') grown in plastic pots in a greenhouse were used as male parents. Their pollen was collected at anthesis and kept at $-20^{\circ} \mathrm{C}$.

\section{Cut-style pollination and ovary slice culture}

Cut-style pollination (Asano and Myodo, 1977; Van Tuyl et al., 1991) was performed in August 2002 and 2003. Ovaries were collected 15 days after cut-style pollination and surface sterilized as described by Obata et al. (2000). Ovary-slice culture (Hayashi et al., 1986; Kanoh et al., 1988) was then carried out. Ovaries were sliced into approximately 2-mm thick disks. Each disk contained an average of approximately 30 ovules (Hayashi et al., 1986). The sliced disks were placed horizontally on MS medium (Murashige and Skoog, $1962)$ in a test tube $(\phi=18 \times 180 \mathrm{~mm})$. The MS medium was supplemented with $40 \mathrm{~g} \cdot \mathrm{L}^{-1}$ sucrose, $40 \mathrm{~g} \cdot \mathrm{L}^{-1} \mathrm{D}$ mannitol, and $2.5 \mathrm{~g} \cdot \mathrm{L}^{-1}$ gellan gum, and the $\mathrm{pH}$ was adjusted to 5.8 prior to autoclaving at $121^{\circ} \mathrm{C}$ for $20 \mathrm{~min}$.

The explants were incubated under dark conditions at $25^{\circ} \mathrm{C}$ for four weeks and then placed at $25^{\circ} \mathrm{C}$ under illumination ( $16 \mathrm{~h}$ daylength, $45 \mu \mathrm{mol} \cdot \mathrm{m}^{-2} \cdot \mathrm{s}^{-1}$ ). Ovule germination was recorded until eight months after the culture. The germinated ovules were detached from the placental tissue and subcultured in a test tube $(\phi=18 \times$ $180 \mathrm{~mm}$ ) containing $15 \mathrm{~mL}$ of subculture medium comprising half-strength MS medium supplemented with $20 \mathrm{~g} \cdot \mathrm{L}^{-1}$ sucrose and $2.5 \mathrm{~g} \cdot \mathrm{L}^{-1}$ gellan gum at $25^{\circ} \mathrm{C}$ under illumination.

\section{Hybrid confirmation}

The produced plants were subjected to isozyme analysis to confirm their hybridity. Three enzymes, isocitrate dehydrogenase (IDH; E.C. 1.1.1.41), phosphoglucomutase (PGM; E.C. 2.7.5.1), and 6-phosphogluconate dehydrogenase (6-PGD; E.C. 1.1.1.43), were analyzed according to the method of Hiramatsu et al. (2001).

\section{Growth performance and flower characteristics of acclimated plants}

After subculturing, the plantlets were transplanted to plastic pots $(\phi=9 \mathrm{~cm}$ : one plantlet per pot) containing vermiculite and kept in a humid environment for acclimatization at $20^{\circ} \mathrm{C}$. After 2-6 months of acclimatization culture, they were transplanted to plastic pots $(\phi=15 \mathrm{~cm}$ : one plantlet per pot $)$ containing potting medium (Redi-earth, Sun Gro Horticulture Canada Ltd., British Columbia, Canada) and grown in a greenhouse without controlling temperature, i.e., the minimum was $5^{\circ} \mathrm{C}$ in winter and the maximum was $43^{\circ} \mathrm{C}$ in summer. A liquid fertilizer (Hyponex, Hyponex Japan Co. Ltd., Osaka, Japan) was applied approximately once a month. The number of flowering plants, flower stalks, and days to flowering and flower color were recorded.

\section{Pollen germination of flowered plants}

Pollen was harvested at anthesis and stored at $-20^{\circ} \mathrm{C}$. Pollen fertility was estimated by a germination test performed on solid medium modified by Niimi and Yoshikawa (1992) as follows: 1.0\% (w/v) agar, 10\% $(\mathrm{w} / \mathrm{v})$ sucrose, and $0.1 \%(\mathrm{w} / \mathrm{v})$ boric acid on Petri dishes. Pollen grains were scattered over the surface of the medium, and the Petri dishes were placed at $25^{\circ} \mathrm{C}$ for six hours in dark conditions. Germination was observed under an optical microscope (E800, Nikon Co., Tokyo, Japan). Pollen grains were considered to have germinated when their pollen tube length was longer than the diameter of the pollen grain. For each plant, 200 pollen grains were observed.

\section{Results}

Germination of cultured ovules was observed in all nine interspecific cross combinations, and the germination rate was in the range of $0.2-7.7 \%$ (Table 1 ). All 53 acclimated plants from interspecific crosses possessed both maternal and paternal allozyme marker bands of IDH, 6-PGD, and PGM.

Two of three self-pollinated L. formosanum progenies and 30 of 53 acclimated progenies bolted and reached anthesis during the second year of cultivation (Table 2). It took 651 (in L. formosanum $\times$ 'Pink Tiger') to 707 (in L. formosanum $\times$ L. speciosum) days from the time of pollination to anthesis. Eleven of the flowered progenies produced two or more flower stalks (Table 3). A maximum of four flower stalks was observed in L. formosanum $\times$ 'Pink Tiger' (Table 3 ).

Obtained plants expressed various flower shapes and perianth colors (Table 4). Bowl-shaped flowers were observed in interspecific crosses with L. auratum, 'Lollypop' and 'Pink Tiger'; on the other hand, trumpetshaped flowers were observed with L. speciosum, L. regale, and 'African Queen'. Entirely colored flowers were induced in crosses with 'Lollypop' and 'Pink Tiger'. L. formosanum × 'Lollypop' plants produced pale reddish purple flowers with a yellowish cream brush mark toward the inner base of perinaths (Fig. 1A). The cross combination of L. formosanum $\times$ 'Pink Tiger' produced two types of progenies; three had pink perianths with carmine spots (Fig. 1B); while seven had a white perianths with carmine spots (Fig. 1C). L. formosanum $\times$ L. auratum had white perianths with pink stripes along nectary furrows (Fig. 1D) and L. formosanum $\times$ L. speciosum showed white flowers 
Table 1. Ovule germination in self-pollinated Lilium formosanum and nine interspecific cross combinations using Lilium formosanum as the female parent.

\begin{tabular}{|c|c|c|c|c|}
\hline Pollen parent & Taxonomic group ${ }^{z}$ & Number of ovules cultured & Number of genimations & $\%$ of germination ${ }^{\mathrm{x}}$ \\
\hline \multicolumn{5}{|l|}{ Control } \\
\hline L. formosanum & Leucolirion $6 b$ & 900 & 65 & 7.2 \\
\hline \multicolumn{5}{|l|}{ Interspecific cross } \\
\hline L. auratum & Archelirion & 2190 & 74 & 3.4 \\
\hline L. speciosum & Archelirion & 630 & 11 & 1.7 \\
\hline L. regale & Leucolirion $6 a$ & 300 & 6 & 2.0 \\
\hline 'Lollypop' & Asiatic hybrid & 1260 & 39 & 3.1 \\
\hline 'Pink Tiger' & Asiatic hybrid & 1560 & 120 & 7.7 \\
\hline 'Zaza' & Asiatic hybrid & 990 & 37 & 3.7 \\
\hline 'Le Reve' & Oriental hybrid & 720 & 17 & 2.4 \\
\hline 'Marco Polo' & Oriental hybrid & 300 & 4 & 1.3 \\
\hline 'African Queen' & Trumpet hybrid & 1050 & 2 & 0.2 \\
\hline
\end{tabular}

${ }^{\mathrm{z}}$ According to Comber (1949).

${ }^{y}$ Number of ovules cultured $=$ number of disks $\times 30$ (Hayashi et al., 1986).

$\times \%$ of germination $=$ Number of germinated/cultured ovules $\times 100$.

Table 2. Growth performance of self-pollinated progenies of Lilium formosanum and hybrids from nine interspecific combination crosses using L. formosanum as the female parent.

\begin{tabular}{|c|c|c|c|c|c|c|}
\hline \multirow[b]{2}{*}{ Pollen parent } & \multirow{2}{*}{$\begin{array}{l}\text { Number of plants } \\
\text { acclimatized }\end{array}$} & \multirow{2}{*}{$\begin{array}{c}\text { Number of plants }(\%) \\
\text { flowering } \\
\text { in the second year }\end{array}$} & \multirow{2}{*}{$\begin{array}{l}\text { Days from pollination } \\
\text { to first anthesis } \\
\text { (Ave. }(\max -\min ))\end{array}$} & \multicolumn{3}{|c|}{ Number of plants } \\
\hline & & & & $\begin{array}{l}\text { Flowered in } \\
\text { the third year }\end{array}$ & $\begin{array}{l}\text { Died in the } \\
\text { third year }\end{array}$ & $\begin{array}{c}\text { Died before } \\
\text { flowering }\end{array}$ \\
\hline \multicolumn{7}{|l|}{ Control } \\
\hline L. formosanum & 3 & $2(66.7)$ & $716.0(712-720)$ & 0 & 3 & 1 \\
\hline \multicolumn{7}{|l|}{ Interspecific cross } \\
\hline L. auratum & 15 & $9(60.0)$ & $659.3(655-665)$ & 0 & 15 & 6 \\
\hline L. speciosum & 5 & $2(40.0)$ & 706.5 (706-707) & 1 & 4 & 3 \\
\hline L. regale & 3 & $3(100)$ & $656.7(654-658)$ & 0 & 3 & 0 \\
\hline 'Lollypop' & 3 & $2(66.7)$ & $668.5(667-670)$ & 0 & 2 & 1 \\
\hline 'Pink Tiger' & 15 & $10(66.7)$ & $663.3(651-681)$ & 2 & 11 & 3 \\
\hline 'Zaza' & 4 & $1(25.0)$ & 656 & 0 & 4 & 3 \\
\hline 'Le Reve' & 3 & $1(33.3)$ & 663 & 0 & 3 & 2 \\
\hline 'Marco Polo' & 3 & $1(33.3)$ & 666 & 0 & 2 & 2 \\
\hline ‘African Queen’ & 2 & $1(50.0)$ & 655 & 0 & 1 & 1 \\
\hline Total $^{\mathrm{z}}$ & 53 & $30(55.6)$ & $666.0(651-707)$ & 3 & 45 & 20 \\
\hline
\end{tabular}

${ }^{\mathrm{z}}$ Self-pollinated progenies of $L$. formosanum were excluded.

with brushed pink toward the inner base (Fig. 1E). A pure white flower was observed in L. formosanum $\times$ L. regale (Fig. $1 \mathrm{~F}$ ) and white perianths with narrow pale purple stripes outside were observed in L. formosanum $\times$ 'African Queen' (Fig. 1G). All flowers obtained from L. formosanum $\times$ 'Zaza', L. formosanum $\times$ 'Le Reve', and L. formosanum $\times$ 'Marco Polo' were white, but their flowers developed abnormally and perianths were separated (data not shown).

Except for progenies from crosses with 'Le Reve', 'Marco Polo', and 'Zaza', most flowered progenies developed anthers normally and produced many pollen grains. No pollen germination on artificial medium was observed (data not shown). In the third year of cultivation, 48 of the acclimated plants (45 progenies from the interspecific crosses and three of self-pollinated progenies of L. formosanum) produced shoots with malformed leaves and flowers, and they ultimately died (Table 2).

\section{Discussion}

Isozyme analysis suggests that plants obtained from the nine intersectional crosses were hybrids. To our knowledge, there are only three studies in which interspecific hybrids were produced using L. formosanum, i.e., L. formosanum $\times$ L. longiflorum (Shimizu, 1971), L. formosanum $\times$ L. speciosum (Asano, 1978), and $L$. formosanum $\times L$. japonicum Thunb. (Inagaki and Otsuka, 2001). Hybrids from eight cross combinations are produced for the first time in the present study. This 
result indicates that $L$. formosanum has a wide range of cross-compatibility as a female parent with regard to producing intersectional hybrids.

About 22-24 months after pollination, 30 (56.6\%) of the 53 hybrids obtained in this study reached anthesis (Table 2), indicating that they reached anthesis within

Table 3. Multiple shooting of flower stalks in self-pollinated progenies of Lilium formosanum and hybrids from nine interspecific combination crosses using $L$. formosanum as the female parent.

\begin{tabular}{|c|c|c|c|c|c|}
\hline \multirow[t]{2}{*}{ Pollen parent } & \multirow{2}{*}{$\begin{array}{l}\text { Number of } \\
\text { plants tested }\end{array}$} & \multicolumn{4}{|c|}{$\begin{array}{c}\text { Number of plants with indicated } \\
\text { number of flower stalks }\end{array}$} \\
\hline & & 1 & 2 & 3 & 4 \\
\hline \multicolumn{6}{|l|}{ Control } \\
\hline L. formosanum & 2 & & 2 & & \\
\hline \multicolumn{6}{|l|}{ Interspecific cross } \\
\hline L. auratum & 9 & 6 & 3 & & \\
\hline L. speciosum & 2 & 1 & 1 & & \\
\hline L. regale & 3 & 2 & 1 & & \\
\hline 'Lollypop' & 2 & 1 & 1 & & \\
\hline 'Pink Tiger’ & 10 & 6 & 2 & 1 & 1 \\
\hline 'Zaza' & 1 & 1 & & & \\
\hline 'Le Reve' & 1 & 1 & & & \\
\hline 'Marco Polo' & 1 & 1 & & & \\
\hline 'African Queen' & 1 & & & 1 & \\
\hline Total $^{y}$ & 30 & 19 & 8 & 2 & 1 \\
\hline
\end{tabular}

${ }^{\mathrm{z}}$ Reached anthesis in the second year after pollination.

${ }^{y}$ Self-pollinated progenies of $L$. formosanum were excluded.
24 months after germination. Although L. formosanum progenies established from natural mature seeds normally reach anthesis within about 12 months after germination (Hiramatsu et al., 2002; McRae, 1998; Wilson, 1925), self-pollinated $L$. formosanum progenies derived from ovary-slice culture yielded similar results to the interspecific hybrids obtained in this study (Table 2). Anthesis in the second year could be attributed to difficulty in achieving maturation and the subsequent germination of extremely immature embryos aged only 15 days in the present experiment. It seems that the 'precocious flowering' ability of $L$. formosanum appeared dominantly, at least in hybrids that reached anthesis within 24 months after germination. Our method could be applicable to intersectional hybrids obtained using $L . \times$ formolongi as a female plant through embryorescue techniques that flowered in the second year of acclimatization (Fukai et al., 2002; Fukai and Tsuji, 2004; Suzuki and Shoji, 1992).

Lilium formosanum showed a maximum differentiation of 6.2 flower stalks within a year when grown outdoors (Inagaki, 2002). In most of the other species and commercial cultivars of Lilium, only one flower stalk emerges within a year (McRae, 1998). Thus, the expression of multiple shooting with more than two flower stalks in $11(36.7 \%)$ of the flowered hybrids (Table 3) also indicates the inheritance of this trait from L. formosanum. Multiple shooting was also observed in 'Li-9', which is a hybrid between 'Mona' $\times$ L. concolor Salisb. var. pulchellum (Fisch.) Baker (Oomiya et al.,

Table 4. Flower shapes and perianth colors of pollen parents, self-pollinated progenies of Lilium formosanum and hybrids from nine interspecific combination crosses using L. formosanum as the female parent.

\begin{tabular}{|c|c|c|c|c|c|}
\hline \multicolumn{3}{|c|}{ Pollen parent } & \multicolumn{3}{|c|}{ Produced hybrid } \\
\hline $\begin{array}{l}\text { Species or } \\
\text { cultivar }\end{array}$ & Flower shape & Perianth color & Flower shape & Perianth color & $\begin{array}{c}\text { Number of } \\
\text { hybrids obtained }\end{array}$ \\
\hline \multicolumn{6}{|l|}{ Control } \\
\hline L. formosanum & Trumpet & White & Trumpet & White & 2 \\
\hline \multicolumn{6}{|l|}{ Interspecific cross } \\
\hline L. auratum & Bowl & $\begin{array}{l}\text { White with golden-yellow central } \\
\text { stripes and carmine spots and papillae }\end{array}$ & Bowl & $\begin{array}{l}\text { White with pink stripes along } \\
\text { nectary furrows }\end{array}$ & 9 \\
\hline L. speciosum & Turk's-cup & $\begin{array}{l}\text { Pink to crimson with very undulate } \\
\text { margins, sprinkled with carmine spots } \\
\text { and papillae }\end{array}$ & Trumpet & $\begin{array}{l}\text { White with brushed pink toward } \\
\text { inner base }\end{array}$ & 2 \\
\hline L. regale & Trumpet & $\begin{array}{l}\text { White with a chrome-yellow throat } \\
\text { inside, rose-purple outside }\end{array}$ & Trumpet & Pure white & 3 \\
\hline 'Lollypop' & Bowl & White with bright cherry pink tips & Bowl & $\begin{array}{l}\text { Pale reddish purple with white } \\
\text { stripes }\end{array}$ & 2 \\
\hline \multirow[t]{2}{*}{ 'Pink Tiger' } & Bowl & Pink with carmine spots & Bowl & Pink with carmine spots & 3 \\
\hline & & & Bowl & White with carmine spots & 7 \\
\hline 'Zaza' & Bowl & White with carmine spots & Abnormal & White with carmine spots & 1 \\
\hline 'Le Reve' & Bowl & Light-pink with carmine spots & Abnormal & White & 1 \\
\hline 'Marco Polo' & Bowl & White infused with light pink & Abnormal & White & 1 \\
\hline 'African Queen' & Trumpet & $\begin{array}{l}\text { Brownish purple outside, yellow to } \\
\text { apricot inside }\end{array}$ & Trumpet & $\begin{array}{l}\text { White with narrow pale purple } \\
\text { stripes outside }\end{array}$ & 1 \\
\hline
\end{tabular}

\footnotetext{
${ }^{\mathrm{z}}$ Reached anthesis in the second year after pollination.
} 

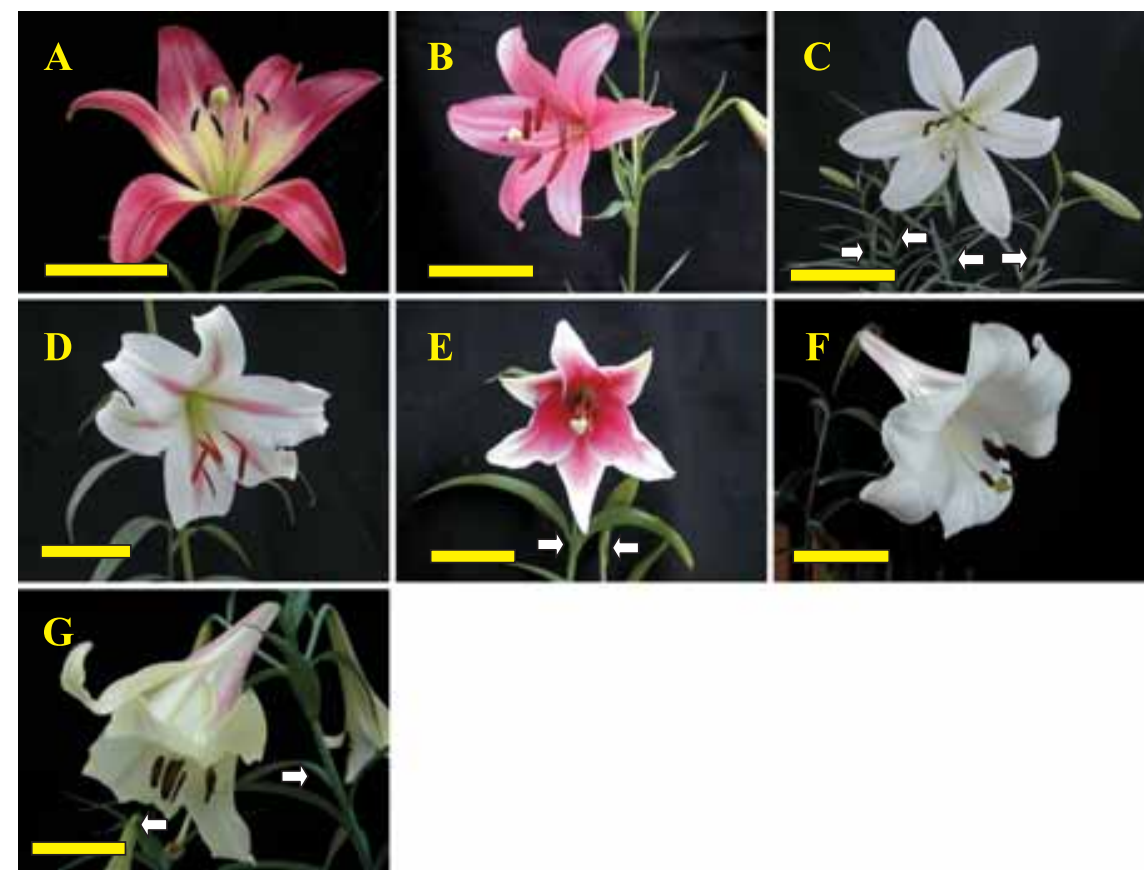

Fig. 1. Flowers of interspecific hybrids. (A) L. formosanum $\times$ 'Lollypop', (B, C) L. formosanum $\times$ 'Pink Tiger', (D) L. formosanum $\times$ L. auratum, (E) L. formosanum $\times$ L. speciosum, $(\mathrm{F})$ L. formosanum $\times$ L. regale, $(\mathrm{G})$ L. formosanum $\times$ 'African Queen'. Scale bars $=5 \mathrm{~cm}$. Arrows indicate flower stalks.

2005); nevertheless, the factors controlling the trait have not been revealed. Convenient artificial methods for controlling the multiple shooting trait will allow its commercial promotion.

The five hybrids obtained in this study had colored flowers, four of which showed both 'precocious flowering' and multiple shooting. Hybrids with all three traits were observed in crosses of $L$. formosanum $\times$ Asiatic hybrids with colored flowers. Breeding new cultivars with these three favorable traits is possible by cross combinations of $L$. formosanum $\times$ Asiatic hybrids.

Intersectional hybrids appear to inherit not only favorable traits but also unfavorable traits from L. formosanum. In the third year of cultivation, 45 hybrids produced shoots with malformed leaves and flowers and some bulbs finally rotted (Table 2). This is quite similar to the growth features of $L$. formosanum after virus infection (McRae, 1998). Viral disease is a serious concern in the cultivation of L. formosanum (Hiramatsu et al., 2006; McRae, 1998) and species of section Archelirion (Shimizu, 1971). This is consistent with our result that growth abnormality was quite severe in intersectional hybrids between $L$. formosanum and L. auratum of section Archelirion.

To utilize the traits of 'precocious flowering', multiple shooting, and flower colors and to avoid virus-disease infection, the intersectional hybrids produced in this experiment should recover their sexual reproductive fertility and should be propagated by seeds. Many interspecific lily hybrids are sterile at the diploid level (Asano, 1978, 1980; Van Tuyl et al., 1986). $F_{1}$ sterility is, however, restored at the tetraploid level (Asano, 1982; Van Tuyl et al., 1997). Induction of amphidiploids by chromosome doubling and crosses within or among induced amphidiploids may provide better recombinant types.

Therefore, in conclusion, breeding new hybrids with 'precocious flowering' ability, multiple shooting of flower stalks in L. formosanum, and with colored and bowl-shaped flowers like the paternal plant is possible; however, it is necessary to overcome fertility problems to supply the hybrids commercially by seeds.

\section{Literature Cited}

Asano, Y. 1978. Studies on crosses between distantly related species of lilies III. New hybrids obtained through embryo culture. J. Japan. Soc. Hort. Sci. 47: 401-414 (In Japanese with English abstract).

Asano, Y. 1980. Studies on crosses between distantly related species of lilies IV. The culture of immature hybrid embryos 0.3-0.4 mm long. J. Japan. Soc. Hort. Sci. 49: 114-118 (In Japanese with English abstract).

Asano, Y. 1982. Overcoming interspecific hybrid sterility in Lilium. J. Japan. Soc. Hort. Sci. 51: 75-81.

Asano, Y. and H. Myodo. 1977. Studies on crosses between distantly related species of lilies I. For the intrastylar pollination technique. J. Japan. Soc. Hort. Sci. 46: 59-65 (In Japanese with English abstract).

Comber, H. F. 1949. A new classification of the genus Lilium. Lily Yearbook RHS 13: 86-105.

Enami, A. 2005. Bulb production in Oriental hybrid lilies. p. 559562. In: Nogyogijutsutaikei Kaki, vol. 10 (In Japanese). Nousangyosonbunkakyoukai, Tokyo.

Fukai, S., M. Ohmatsu, A. Kimura, C. Ikoma, T. Nagamidori and 
M. Goi. 2002. Effect of style length in cut style pollination on production of LO interspecific hybrid lilies and the characteristics of obtained hybrids. Tech. Bull. Fac. Agr. Kagawa Univ. 54: 29-33.

Fukai, S. and K. Tsuji. 2004. Interspecific hybrids between Lilium $\times$ formolongi and some Asian trumpet species. J. Japan. Soc. Hort. Sci. 73: 447-452.

Hayashi, M., K. Kanoh, Y. Serizawa and E. Yoon. 1986. Ovary slice culture of Lilium formosanum Wallace. Japan. J. Breed. 36: 304-308.

Hiramatsu, M., K. Ii, H. Okubo, K. L. Huang and C. W. Huang. 2001. Biogeography and origin of Lilium longiflorum and L. formosanum (Liliaceae) endemic to the Ryukyu Archipelago and Taiwan as determined by allozyme diversity. Amer. J. Bot. 88: 1230-1239.

Hiramatsu, M., H. Okubo, K. Nakano, C. L. Huang and K. L. Huang. 2006. Seedling growth response to biotic and abiotic stresses in Lilium longiflorum and L. formosanum in relation to their life history strategies. J. Fac. Agr., Kyushu Univ. 51: 83-86.

Hiramatsu, M., H. Okubo, K. Yoshimura, K. L. Huang and C. W. Huang. 2002. Biogeography and origin of Lilium longiflorum and L. formosanum II-Intra and interspecific variation in stem leaf morphology, flowering rate and individual net production during the first year seedling growth. Acta Hort. 570: 331-338.

Inagaki, H. 2002. Research on self fertilization in Lilium formosanum Wallace. J. Weed Sci. Tech. 47: 147-152 (In Japanese with English abstract).

Inagaki, H. and H. Otsuka. 2001. Interspecific hybrids of Lilium formosanum Wallace. with Lilium japonicum Thunb. through embryo culture. Bull. Shizuoka Agr. Exp. Sta. 46: 69-76 (In Japanese with English abstract).

Kanoh, K., M. Hayash, Y. Serizawa and T. Konishi. 1988. Production of interspecific hybrids between Lilium longiflorum and $L . \times$ elegance by ovary slice culture. Japan. J. Breed. 38: 278-282.

Matsumoto, O., Y. Okafuji, T. Mitsunaga and T. Nakamura. 1998. Breeding of new lily cultivars Marriage series by ovule culture. Bull. Yamaguchi Veg. Orn. Crops Exp. Sta. 49: 14 (In Japanese with English abstract).

McRae, E. A. 1998. Lilies. A guide for growers and collectors. Timber Press, Portland.

Mitsunaga, T., Y. Okafuji and O. Matsumoto. 1996. Production of interspecific hybrids of $L . \times$ formolong $i$ with $L . \times$ elegance through ovule culture and their characteristics. Bull. Yamaguchi Agric. Exp. Sta. 47: 19-25 (In Japanese with English abstract).
Mitsunaga, T., H. Ozeki, Y. Okafuji, Y. Yamamoto and O. Matsumoto. 2002. Breeding of new lily cultivars Marriage series by ovule culture. Bull. Yamaguchi Agric. Exp. Sta. 53: 50-58 (In Japanese with English abstract).

Murashige, T. and F. Skoog. 1962. A revised medium for rapid growth and bioassays with tobacco tissue cultures. Physiol. Plant. 15: 473-497.

Niimi, Y. and Y. Yoshikawa. 1992. A study on the storage of Lilium pollen. J. Japan. Soc. Hort. Sci. 61: 399-403.

Obata, Y., Y. Niimi, M. Nakano, K. Okazaki and I. Miyajima. 2000. Interspecific hybrids between Lilium nobilissimum and $L$. regale produced via ovules-with-placental-tissue culture. Sci. Hort. 84: 191-204.

Okada, M., A. Namachi and M. Matsumoto. 1997. Introduction of triploid LA hybrid lilies by the hybridization between tetraploid Lilium $\times$ formolomgi hort, and diploid Asiatic hybrid lilies. Bull. Kochi Agr. Res. Cent. 6: 8-12 (In Japanese with English abstract).

Okazaki, K., Y. Umeda, O. Urashima. J. Kawada, M. Kunishige and K. Murakami. 1992. Interspecific hybrids of Lilium longiflorum and $L . \times$ formolongi with $L$. rubellum and L. japonicum through embryo culture. J. Japan. Soc. Hort. Sci. 60: 997-1002 (In Japanese with English abstract).

Oomiya, T., H. Tamagake, S. Tsutsui and M. Ubukata. 2005. A new cultivar of the Asiatic hybrid lily, 'Li-9', with multiple scapes and small flowers. Acta Hort. 673: 559-562.

Shii, C. T. 1983. The distribution and variation of Lilium formosanum Wall. and L. longiflorum Thunb. in Taiwan. Lily Yearbook NALS 36: 48-51.

Shimizu, M. 1971. Lilies of Japan (In Japanese). Seibundo Shinkosha, Tokyo.

Suzuki, S. and K. Shoji. 1992. Interspecific hybridization of Lilium $\times$ formolongi, L. auratum $\times$ L. rebellum through embryo culture. Bull. Miyagi Agr. Hort. Res. Cent. 58: 1-9 (In Japanese with English abstract).

Van Tuyl, J. M., J. Franken, R. C. Jongerius, C. A. M. Look and T. A. M. Kwakkenbos. 1986. Interspecific hybridization in Lilium. Acta Hort. 177: 591-595.

Van Tuyl, J. M., M. P. Van Diën, M. G. M. Van Creij, T. C. M. Van Kleinwee, J. Franken and R. J. Bino. 1991. Application of in vitro pollination, ovary culture, ovule culture and embryo rescue for overcoming incongruity barriers in interspecific Lilium crosses. Plant Sci. 74: 115-126.

Van Tuyl, J. M., H. S. Chi, B. C. M. Van Kronenburg and B. Meijer. 1997. Interspecific lily hybrids: a promise for the future. Acta Hort. 430: 539-544.

Wilson, E. H. 1925. The lilies of eastern Asia. Dulau and Company, London. 